\title{
Hydrographic data from the GEF Patagonia cruises
}

\author{
M. Charo ${ }^{1}$ and A. R. Piola ${ }^{1,2}$ \\ ${ }^{1}$ Departamento Oceanografía, Servicio Hidrografía Naval, Buenos Aires, Argentina \\ ${ }^{2}$ Departamento de Ciencias de la Atmósfera y los Océanos, FCEN, Universidad de Buenos Aires, and \\ UMI-IFAECI, Buenos Aires, Argentina
}

Correspondence to: M. Charo (mcharo@hidro.gov.ar)

Received: 21 January 2014 - Published in Earth Syst. Sci. Data Discuss.: 6 February 2014

Revised: 5 May 2014 - Accepted: 16 May 2014 - Published: 19 June 2014

\begin{abstract}
The hydrographic data reported here were collected within the framework of the Coastal Contamination, Prevention and Marine Management Project (Global Environment Facility (GEF) Patagonia), which was part of the scientific agenda of the United Nations Development Program (UNDP). The project goal was to strengthen efforts to improve sustainable management of marine biodiversity and reduce pollution of the Patagonia marine environment. The observational component of the project included three multidisciplinary oceanographic cruises designed to improve the knowledge base regarding the marine environment and to determine the seasonal variability of physical, biological and chemical properties of highly productive regions in the southwest South Atlantic continental shelf. The cruises were carried out on board R/V ARA Puerto Deseado, in October 2005 and March and September 2006. On each cruise, hydrographic stations were occupied along cross-shelf sections spanning the shelf from nearshore to the western boundary currents between $38^{\circ}$ and $55^{\circ} \mathrm{S}$. This paper reports the quasi-continuous vertical profiles (conductivity-temperature-depth (CTD) profiles) and underway surface temperature and salinity data collected during the GEF Patagonia cruises. These data sets are available at the National Oceanographic Data Center, NOAA, US, doi:10.7289/V5RN35S0.
\end{abstract}

\section{Data coverage and parameters measured}

Repository reference: doi:10.7289/V5RN35S0.

CTD continuous profiles and thermosalinograph data

Available at: doi:10.7289/V5RN35S0

Coverage: $38-55^{\circ} \mathrm{S}, 70-54^{\circ} \mathrm{W}$

Location name: western South Atlantic, Patagonia

Continental Shelf

Date/time start: 8 October 2005

Date/time end: 25 September 2006

\section{Introduction}

The Argentine continental shelf is one of the largest shelf areas in the world ocean and comprises the Patagonian Shelf Large Marine Ecosystem (PLME; Heileman, 2009). The Atlantic Patagonia continental shelf extends from $55^{\circ} \mathrm{S}$ at the tip of Tierra del Fuego to approximately $39^{\circ} \mathrm{S}$. The shelf is a shallow submerged plateau, which is very wide in the south $(\sim 850 \mathrm{~km})$ and narrows toward the north. The offshore edge is marked by a sharp change in bottom slope located at 115-240 m depth (Parker et al., 1997). This region is one of the most productive in the Southern Hemisphere and supports a wide variety of marine life (Falabella et al., 2009). In situ estimates of primary production in austral spring range between $\sim 200 \mathrm{mg} \mathrm{C} \mathrm{m}^{-2} \mathrm{~d}^{-1}$ and $>3000 \mathrm{mg} \mathrm{C} \mathrm{m}^{-2} \mathrm{~d}^{-1}$ near frontal regions (Lutz et al., 2010). The high biological productivity of the PLME sustains intense fishing activity, mostly by Argentine fleets but also by other international fleets (Heileman, 2009). In addition, this large primary production leads to the absorption of large quantities of carbon dioxide from the atmosphere (Bianchi et al., 2005) accounting for about $1 \%$ of the global ocean's net annual $\mathrm{CO}_{2}$ uptake, almost four times the mean rate of $\mathrm{CO}_{2}$ uptake of the global ocean (Bianchi et al., 2009).

The high production is mostly associated with various shelf and shelf-break fronts generated by strong winds, largeamplitude tides, large buoyant discharges and the proximity 


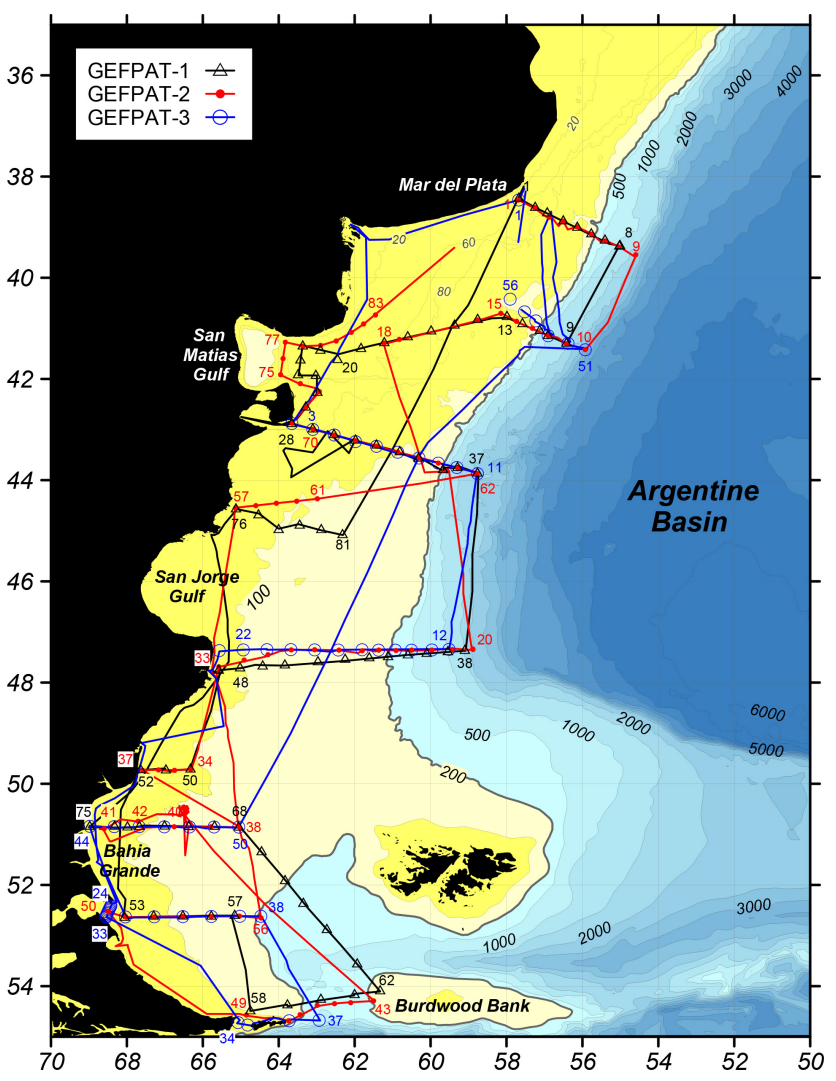

Figure 1. Location of hydrographic stations occupied during the GEF Patagonia cruises (symbols) and cruise tracks along which surface observations were collected (lines). Selected station numbers for each cruise are shown in the same colors. The background shading and contours indicate bottom topography in meters.

of the nutrient-rich Malvinas Current (e.g., Acha et al., 2004; Saraceno et al., 2005; Palma et al., 2008; Matano and Palma, 2008; Matano et al., 2010). To determinate the seasonal variability of physical, chemical and biological properties and improve the knowledge base of the Patagonia marine environment and its biodiversity, three oceanographic cruises were carried out on board R/V ARA Puerto Deseado as part of the Global Environment Facility (GEF) Patagonia project (Fig. 1). The cruises were carried out in October 2005 (GEFPAT-1) and March (GEFPAT-2) and September 2006 (GEFPAT-3). Each survey consisted of the occupation of seven to nine cross-shelf sections from the nearshore area to the upper slope of the western Argentine Basin close to the $2000 \mathrm{~m}$ isobath. The cruise design provided quasisynoptic observations of the nearshore tidal fronts, the midshelf region, the shelf-break front and the western edge of the Malvinas Current (e.g., Romero et al., 2006). We briefly describe procedures of acquisition and processing of vertical conductivity-temperature-depth (CTD) profiles and underway surface temperature and salinity data.

\section{Hydrographic stations}

\subsection{CTD profiles}

At each station a vertical quasi-continuous CTD profile was collected with a Sea-Bird Electronics model 911plus unit, equipped with fluorescence and turbidity sensors in GEFPAT-1, an oxygen sensor in GEFPAT-2, and oxygen, fluorescence and turbidity sensors in GEFPAT-3. Additional redundant temperature and conductivity sensors were used in some stations during GEFPAT-3. Table 1 summarizes the CTD sensors used in each cruise. Most vertical profiles reached to within $\sim 5 \mathrm{~m}$ from the bottom within the continental shelf and $10 \mathrm{~m}$ from the bottom at stations deeper than $200 \mathrm{~m}$, except under adverse weather conditions or when the distance of the package from the bottom was uncertain, such as over regions with a steep bottom slope. The CTD was mounted with a rosette sampler and the package was deployed on a conducting cable, which allowed for real-time data acquisition and display on board. A General Oceanics (model GO 1015) 12-bottle water sampler was employed in GEFPAT-1 whereas a Sea-Bird Carousel (model SBE 32) 24-bottle water sampler was employed in GEFPAT-2 and GEFPAT-3. Both models held 5 L Niskin bottles. Duplicate CTD casts were carried out in GEFPAT-1 to collect water samples for ancillary biological programs. Duplicate casts were identified by station file names with the suffix b. Downcast profile data were reported because during downcast the CTD sensors sample the water column with minimal interference from the underwater package. However, in some stations that presented noisy data during the down-cast, up-cast data were reported. Down-cast (up-cast) file names were prefixed by d (u). Station date and times are reported in UTC.

\subsection{CTD data processing}

CTD data were post-processed according to common standards, using Sea-Bird Data Processing software routines (Seasoft-Win32, http://www.seabird.com/software/sswin. htm, SBE, 2005). The nominal calibrations were used for data acquisition. Final conductivity calibration was determined empirically by comparison with the salinities of discrete water samples taken during each up-cast. Conductivity and dissolved oxygen sensors were calibrated as described in the following sections. Fluorescence and turbidity data are reported based on factory calibrations only.

Data were subsequently averaged at 1 dbar pressure intervals. The data for each cast were inspected and any remaining density spikes removed by linear interpolation of the original temperature and conductivity data and all derived parameters recalculated at that level. 
Table 1. Summary of CTD sensors used in GEF Patagonia cruises.

\begin{tabular}{|c|c|c|c|c|c|c|}
\hline $\begin{array}{l}\text { Cruise } \\
\text { date }\end{array}$ & $\begin{array}{l}\text { Station } \\
\text { number }\end{array}$ & Sensor & Model & $\begin{array}{l}\text { Initial } \\
\text { accuracy }\end{array}$ & Serial \# & Cal. date \\
\hline \multirow{7}{*}{$\begin{array}{l}\text { GEFPAT_1 } \\
8-28 \text { Oct } \\
2005\end{array}$} & & Pressure & Digiquartz w/TC 4 & $\begin{array}{l}0.015 \% \text { of } \\
\text { full scale }\end{array}$ & 57472 & 04.05 .94 \\
\hline & 1 & Temperature & SBE 3plus & $0.001{ }^{\circ} \mathrm{C}$ & 031689 & 01.19 .01 \\
\hline & 1 & Conductivity & SBE 4C & $\begin{array}{l}0.0003 \mathrm{~S} \mathrm{~m}^{-1} \\
< \pm 0.002 \mathrm{PSU}^{3}\end{array}$ & 041381 & 01.30 .01 \\
\hline & $2-68,70-81^{1}$ & Temperature & SBE 3plus & & 031691 & 11.05 .94 \\
\hline & $2-68,70-81$ & Conductivity & SBE 4C & & 041382 & 11.04 .94 \\
\hline & $1-68,70-81$ & Fluorescence & $\begin{array}{l}\text { Sea Tech } \\
\text { WET Labs FLF }\end{array}$ & & 2125 & 08.10 .02 \\
\hline & $1-68,70-81$ & Turbidity & $\begin{array}{l}\text { Sea Tech LS6000 } \\
\text { WET Labs LBSS }\end{array}$ & & 495 & 12.08 .00 \\
\hline \multirow{4}{*}{$\begin{array}{l}\text { GEFPAT_2 } \\
10 \text { Mar-1 Apr } \\
2006\end{array}$} & & Pressure & Digiquartz w/TC & & 95796 & 07.22 .05 \\
\hline & $1-83$ & Temperature & SBE 3plus & & 032951 & 07.15 .05 \\
\hline & $1-83$ & Conductivity & SBE 4C & & 042657 & 06.10 .05 \\
\hline & $1-14,38-83^{2}$ & Oxygen & SBE 43 & & 0869 & 07.23 .05 \\
\hline \multirow{9}{*}{$\begin{array}{l}\text { GEFPAT_3 } \\
5-25 \text { Sep } \\
2006\end{array}$} & & Pressure & Digiquartz w/TC & & 95796 & 07.22 .05 \\
\hline & $1-56$ & Temperature 1 & SBE 3plus & & 032951 & 07.15 .05 \\
\hline & $1-56$ & Conductivity 1 & SBE 4C & & 042657 & 06.10 .05 \\
\hline & $24-56$ & Temperature 2 & SBE 3plus & & 031689 & 01.19 .01 \\
\hline & $24-56$ & Conductivity 2 & SBE 4C & & 041381 & 01.30 .01 \\
\hline & $1-56$ & Oxygen & SBE 43 & $\begin{array}{l} \pm 2 \% \text { of } \\
\text { saturation }\end{array}$ & 0869 & 07.23 .05 \\
\hline & $1-56$ & Fluorescence & Seapoint $\mathrm{SCF}^{7}$ & & 2816 & \\
\hline & $1-56$ & Turbidity & Sea Tech LS6000 & & 495 & 12.08 .00 \\
\hline & & & WET Labs LBSS & & & \\
\hline
\end{tabular}

1 Station 69: no CTD profile.

2 Stations 15-37: no oxygen sensor.

3 Salinometer (Practical Salinity Units, PSU).

4 Temp-Comp.

5 Flash Lamp Fluorometer.

${ }^{6}$ Light Back-Scattering Sensor.

7 Seapoint Chorophyll Fluorometer.

\subsection{CTD sensor calibration}

\subsubsection{Temperature}

Temperature sensor SN031691 used in GEFPAT-1 was factory calibrated in 2010 . The pre- and post-cruise calibration data were used to determine the sensor drift, which was used for sensor calibration (SBE, 2010). The laboratory calibrations showed a drift correction of $-0.00037^{\circ} \mathrm{C}_{\text {year }}{ }^{-1}$, corresponding to a temperature offset correction of $0.004{ }^{\circ} \mathrm{C}$ for GEFPAT-1 data.

The temperature sensor SN032951 used in GEFPAT-2 and GEFPAT-3 was factory post-calibrated in 2009. The resulting temperature drift correction was $-0.00006^{\circ} \mathrm{C}_{\text {year }}{ }^{-1}$ corresponding to an offset correction of $0.00004{ }^{\circ} \mathrm{C}$ and $0.00007^{\circ} \mathrm{C}$ for each cruise, respectively. These temperatures offset corrections are lower than sensor resolution $\left(0.0002{ }^{\circ} \mathrm{C}\right)$. Thus, the GEFPAT- 2 and GEFPAT- 3 temperature data do not require calibration for drift.
Temperature sensor SN031689 (secondary sensor for GEFPAT-3) was not factory calibrated after the cruise.

\subsubsection{Conductivity}

On board calibration of the conductivity sensor was performed empirically by comparing its nominally calibrated output against the calculated conductivity values obtained from water sample salinities using the pressure and temperature of the CTD at the time of bottle closure. An estimate of bias (offset) and slope corrections to the nominal factory calibration were determined using a linear least squares fit. For each cruise, bottle conductivities were fitted to CTD conductivities and conductivity differences greater than 2 standard deviations from the fits were rejected.

Vertical profiles of salinity differences between CTD and bottle salinity were plotted to identify suspect water samples caused by leaky Niskin bottles or drawn from regions 

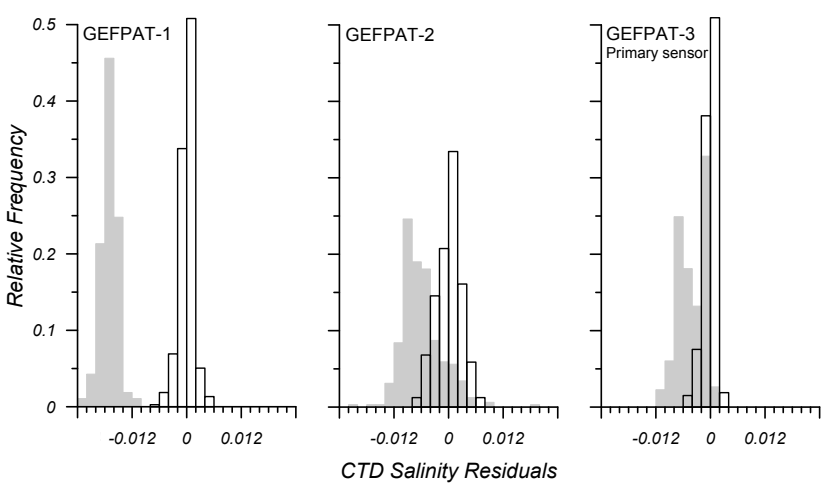

Figure 2. Relative frequency distribution of salinity residuals before (shaded grey) and after (black solid line) CTD calibration for GEF Patagonia cruises.

of relatively large vertical salinity gradients. Also, potential temperature-salinity $(\theta-S)$ diagrams of historical hydrographic data collected in the same region were overlaid to check for consistency. All suspect bottle data were discarded and not used in the CTD calibration process described above.

CTD observations of GEFPAT-2 were collected during a late austral summer, when mid-shelf waters present a strong vertical stratification associated with vertical temperature gradients on the order of $1{ }^{\circ} \mathrm{C} \mathrm{m}^{-1}$. Across these intense temperature gradients, spurious CTD salinity spikes were frequently observed. Salinity spikes were removed based on the comparison with bottle salinities obtained at selected stations where water samples across the thermocline were obtained at $\sim 1 \mathrm{~m}$ resolution. In stations without high-resolution bottle sampling, both down- and up-casts and water sample salinities were combined to reconstruct salinity profiles. The reconstructed data were inspected to check for density inversions, which were removed and filled in by linear interpolation and all derived parameters were recalculated at the interpolated level. Station file names of reconstructed profiles were renamed as the station file name with the suffix re.

To illustrate the quality of the conductivity calibration, Fig. 2 displays the salinity residuals before and after calibration and Table 2 summarizes the comparisons between CTD and water sample salinity for each cruise.

\subsubsection{Dissolved oxygen}

Calibration of the oxygen sensor was performed using a statistical method estimating calibration coefficients for calculating dissolved oxygen in milliliters per liter $\left(\mathrm{mL} \mathrm{L}^{-1}\right)$ from SBE 43 output voltage. The technique requires dissolved oxygen concentrations reported in $\mathrm{mLL}^{-1}$ determined from a range of Winkler-titrated water samples and SBE 43 oxygen voltage outputs measured at the times the water samples were collected (SBE, 2002). Though the sensor manufacturer recommends advancing the oxygen voltage data relative to the CTD pressure (SBE, 2005), we carried out several

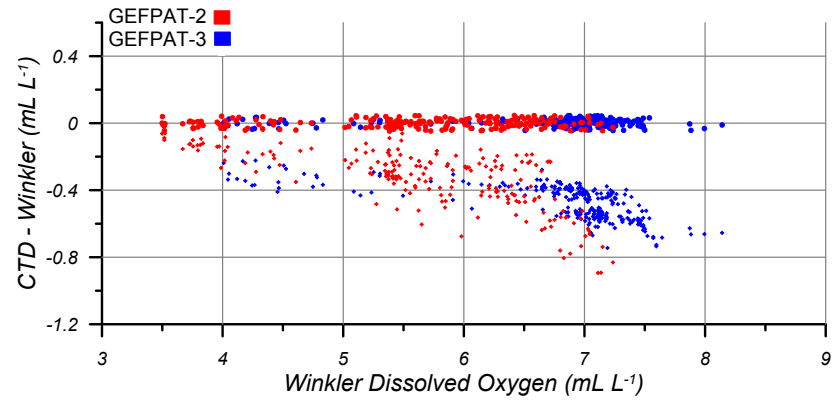

Figure 3. Distribution of dissolved oxygen residuals versus dissolved oxygen concentration (both in $\mathrm{mL} \mathrm{L}^{-1}$ ) before $(+)$ and after (•) SBE 43 sensor calibration for GEFPAT-2 (red) and GEFPAT-3 (blue).

tests and concluded that this alignment led to a larger dissolved oxygen mismatch between CTD and water samples across the thermocline. Thus, no alignment corrections were applied.

The oxygen from water samples was compared with historical data collected in the region to check for consistency and to identify suspicious data. Historical data were obtained from the Argentine Oceanographic Data Center (CEADO, http://www.hidro.gob.ar/ceado/Fq/extrnac. asp\#nacionales). CEADO archive data came from Argentine and international research institutions. The standard deviation of the residuals was approximately $1 \mu \mathrm{mol} \mathrm{kg}{ }^{-1}$. Figure 3 presents the differences between SBE 43 dissolved oxygen before and after calibration and Winkler-titration dissolved oxygen.

\subsection{Water sample analysis}

Water samples at selected levels were taken from $5 \mathrm{~L}$ Niskin bottles for the determination of salinity and dissolved oxygen. Salinity and dissolved oxygen were determined on board. Salinity samples were collected in $200 \mathrm{~mL}$ glass flasks and salinity was determined with a Guildline Autosal 8400B salinometer. The Autosal standardization was carried out with Ocean Scientific International Ltd. (OSIL) standard seawater (SSW) batches P130 (1996) and P141 (2002) for GEFPAT-1, P141 (2002) and P146 (2005) for GEFPAT-2 and P146 (2005) for GEFPAT-3, according to the procedure described in the salinometer technical manual (Guildline, 2004). To test the possible effects of the aging of standard seawater we standardized the instrument with more recent batches $(P 146,2005)$ and then ran samples of P130 (1996). The tests indicated that the conductivity ratios of these batches were within $3 \times 10^{-6}$ of the value indicated by the manufacturer. This indicates that our salinity determinations were not affected by the age of the standard seawater. Salinity values were calculated and reported based in practical salinity units (PSS78, UNESCO, 1981). 
Table 2. Comparison of CTD vs. water sample salinity. Pre- and post-calibration (bold) for each cruise calculated for the whole water column $\left(0<p<p_{\max }\right)$ and below $200 \mathrm{dbar}\left(200<p<p_{\max }\right)$. Number of samples $(N)$ is indicated for each set.

\begin{tabular}{lr|rr|r|rr|r}
\hline Cruise & Station & \multicolumn{2}{|c|}{$0<p<p_{\max }$} & $N$ & \multicolumn{2}{|c|}{$200<p<p_{\max }$} & $N$ \\
& & Mean & Std. dev. & & Mean & Std. dev. & \\
\hline GEFPAT-1 & $1-81$ & -0.017 & 0.0019 & 376 & -0.016 & 0.0012 & 57 \\
& $\mathbf{1 - 8 1}$ & $\mathbf{0 . 0 0 0 1}$ & $\mathbf{0 . 0 0 1 6}$ & $\mathbf{3 7 6}$ & $\mathbf{0 . 0 0 0 5}$ & $\mathbf{0 . 0 0 1 2}$ & $\mathbf{5 7}$ \\
GEFPAT-2 & $1-83$ & -0.0059 & 0.0049 & 323 & -0.0038 & 0.0051 & 44 \\
& $\mathbf{1 - 8 3}$ & $\mathbf{0 . 0 0 0 0}$ & $\mathbf{0 . 0 0 2 7}$ & $\mathbf{3 2 3}$ & $\mathbf{- 0 . 0 0 0 4}$ & $\mathbf{0 . 0 0 3 4}$ & $\mathbf{4 4}$ \\
GEFPAT-3 & $1-56$ & -0.0042 & 0.0028 & 265 & -0.0034 & 0.0025 & 52 \\
& $\mathbf{1 - 5 6}$ & $\mathbf{- 0 . 0 0 0 1}$ & $\mathbf{0 . 0 0 1 3}$ & $\mathbf{2 6 5}$ & $\mathbf{0 . 0 0 0 1}$ & $\mathbf{0 . 0 0 1 2}$ & $\mathbf{5 2}$ \\
GEFPAT-3* & $24-56$ & -0.0130 & 0.0038 & 138 & -0.0105 & 0.0014 & 26 \\
& $\mathbf{2 4 - 5 6}$ & $\mathbf{0 . 0 0 0 1}$ & $\mathbf{0 . 0 0 2 0}$ & $\mathbf{1 3 8}$ & $\mathbf{0 . 0 0 2 4}$ & $\mathbf{0 . 0 0 1 5}$ & $\mathbf{2 6}$ \\
\hline
\end{tabular}

* Secondary sensors.

The double conductivity ratio of SSW during GEFPAT-3, showed a positive trend with time determined from the difference between the beginning and the completion of each run of samples. In order to determine whether the observed drift was due to alteration of the SSW or due to instrument drift, the instrument was standardized with a new vial of SSW at the beginning and at the end of one run. This test revealed an estimated Autosal drift of double conductivity ratio of 0.00013 over a period of $5 \mathrm{~h}$, which is approximately equivalent to a rate of change in salinity of $0.00048 \mathrm{~h}^{-1}$. In addition this test indicates an SSW alteration of 0.0001 in the double conductivity ratio, equivalent to a salinity change of 0.002 during the $5 \mathrm{~h}$ period. These estimates can be considered upper error limits as other salinity sample runs took about the same or shorter time. To account for the salinometer drift for each run a linear trend correction was estimated by a least squares fit and salinity from seawater samples corrected by removing the spurious trend. In GEFPAT-1 and GEFPAT-2 cruises the double conductivity ratio of SSW presented no trends.

Dissolved oxygen was determined with a modified Winkler method (Carpenter, 1965) using an amperometric endpoint detection technique. In the three GEF Patagonia cruises, the dissolved oxygen concentrations were determined with a Mettler DL 21 automatic titration system. Samples were collected in $\sim 125 \mathrm{~mL}$ volume-calibrated borosilicate glass flasks and whole-bottle titration was carried out in the analysis. Standardizations were performed with commercial potassium iodate solutions $(0.01 \mathrm{~N})$ provided by OSIL and also prepared ashore. The thiosulfate solution was standardized at a temperature within $\pm 1^{\circ} \mathrm{C}$ of the temperature at which the oxygen samples were analyzed. Duplicate thiosulfate standardizations were run requiring endpoints to be within $( \pm 0.3 \%)$ of each other.
Table 3. Calibrated thermosalinograph versus water sample salinity comparison for GEF Patagonia cruises. Number of samples $(N)$ is indicated for each cruise.

\begin{tabular}{lrrr}
\hline Cruise & Mean & Std. dev. & $N$ \\
\hline GEFPAT-1 & -0.006 & 0.024 & 61 \\
GEFPAT-2 & -0.006 & 0.019 & 97 \\
GEFPAT-3 & -0.007 & 0.020 & 45 \\
\hline
\end{tabular}

\section{Underway measurements}

Throughout the three cruises underway near-surface $(\sim 3 \mathrm{~m})$ quasi-continuous temperature and salinity data were collected using two Sea-Bird Electronics Seacat 21 thermosalinographs (SN 2310 in GEFPAT-1 and SN 3265 in GEFPAT-2 and GEFPAT-3). The data were recorded every $30 \mathrm{~s}$ and occasionally every $60 \mathrm{~s}$ along some tracks of GEFPAT-2. Bottle salinity samples were taken periodically from the thermosalinograph water intake to verify the thermosalinograph calibration. These water sample salinities were determined on board following the same procedures described above.

Pump malfunctioning, continental near-shore discharges and intense phytoplankton blooms tend to clog the thermosalinograph filter and alter the flow rate. Flow rate disturbances can result in spurious temperature and conductivity fluctuations. At different stages of the Patagonia GEF cruises the thermosalinograph data presented indications of such malfunctioning, which required flow rate readjustment and filter replacement. The calibrated thermosalinograph and surface CTD data were overlaid to identify suspicious data and bad data were removed. To smooth the noise in the thermosalinograph data caused by flow rate disturbances, temperature and conductivity were filtered using a cosine filter with an 11-point window length. Filtering was carried out employing the Window Filter routine available in the SeaBird Data Processing software (SBE, 2005). 


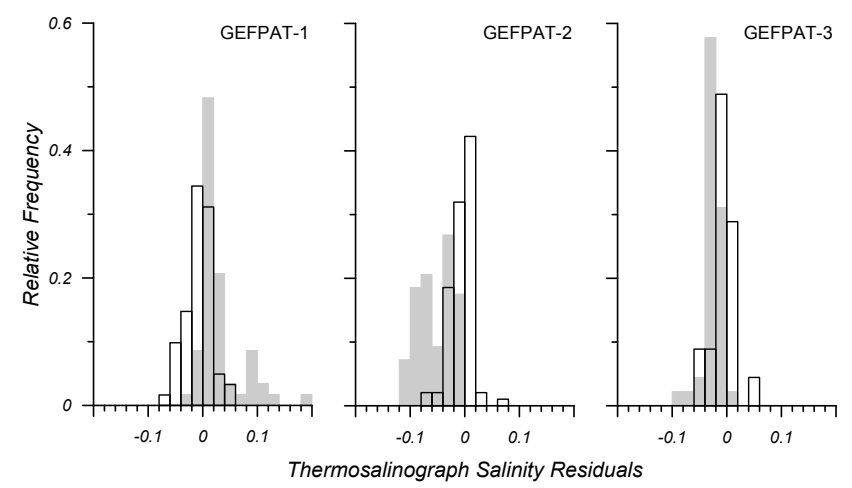

Figure 4. Relative frequency distribution of salinity residuals before (shaded grey) and after (black solid line) thermosalinograph calibration for GEF Patagonia cruises.

\subsection{Sensors calibration}

Thermosalinograph temperature and conductivity were compared with corrected CTD temperature and conductivity data extracted from the 3 dbar level during down- and upcasts for each station. Similar to the CTD calibration procedure, bias (offset) and slope corrections to the nominal calibration were determined from a linear least squares fit to the CTD versus thermosalinograph data of each variable. Values greater than 2 standard deviations from the fits were rejected. In addition, the corrected thermosalinograph salinities were compared with the salinity from bottle samples collected underway to provide independent verification of the calibration described above. Differences between the corrected thermosalinograph salinities and the bottle salinities for each cruise are shown in Fig. 4. Table 3 presents the thermosalinographbottle-salinity comparisons after temperature and conductivity sensors were calibrated.

\section{Data access}

The hydrographic data sets from GEF Patagonia cruises are reported in standard Sea-Bird Converted Data File (cnv) format. Converted files consist of a descriptive header followed by data converted to engineering units. The header contains station time and position information; the name of the raw input data file; the number of data rows and columns; a description of observed and derived variables in each column; interval between rows, scan rate or bin size; and records of all processing steps. The header information is followed by data records with a flag field in the last column, indicating whether the data record was interpolated in the last column. Data from individual stations are presented in separate ASCII character files consisting of $1 \mathrm{dbar}$ data records in physical units. For each cruise, thermosalinograph data are reported in various ASCII files in the original sampling frequency with records in physical units. The thermosalinograph filenames are indicated with prefix "TSG". The data are available at the US National Oceanographic Data Center, NOAA; under doi:10.7289/V5RN35S0.

Acknowledgements. This research was supported by Global Environmental Facility (Grant GEF-BIRF 28385-AR, UNDPARG/02/018) and by Servicio de Hidrografía Naval (Argentina). Additional funding was provided by grants CRN61 and CRN2076 from the Inter-American Institute for Global Change Research (IAI), supported by the US National Science Foundation (grant GEO-0452325). R. A. Guerrero (INIDEP, Argentina) made available a CTD 911plus/Rosette system and an Autosal salinometer used in GEFPAT-1, and other ancillary sensors. Additional technical assistance from INIDEP is gratefully acknowledged. We also thank the crew of R/V ARA Puerto Deseado and the scientific parties of the three cruises for their valuable cooperation at sea.

Edited by: F. Schmitt

\section{References}

Acha, E. M., Mianzan, H., Guerrero R., Favero, M., and Bava, J.: Marine fronts at the continental shelves of austral South America. Physical and ecological processes, J. Marine Syst., 44, 83105, 2004.

Bianchi, A. A., Bianucci, L., Piola, A. R., Pino, D. R., Schloss, I., Poisson, A., and Balestrini, C. F.: Vertical stratification and airsea $\mathrm{CO}_{2}$ fluxes in the Patagonian shelf, J. Geophys. Res., 110, C07003, doi:10.1029/2004JC002488, 2005.

Bianchi, A. A., Pino, D. R., Isbert Perlender, H., Osiroff, A., Segura, V., Lutz, V. A., Luz Clara, M., Balestrini, C. F., and Piola, A. R.: Annual balance and seasonal variability of sea-air $\mathrm{CO}_{2}$ fluxes in the Patagonia Sea: Their relationship with fronts and chlorophyll distribution, J. Geophys. Res., 114, C03018, doi:10.1029/2008JC004854, 2009.

Carpenter, J. H.: The accuracy of the Winkler method for dissolved oxygen analysis. Limnol. Oceanogr., 10, 135-140, 1965.

Falabella, V., Campagna, C., and Croxall, J. (Eds.): Atlas of the Patagonian Sea. Species and Spaces, Wildlife Conservation Society and BirdLife International, Buenos Aires, Argentina, 303 pp., 2009.

Guildline Instruments: Technical manual for Model 9400B "Autosal", TM8400B-L-00, revised November 2006, Guildline Instruments, Smith Falls, Ontario, Canada, 71 pp., 2004.

Heileman S.: XVI-55 Patagonian Shelf LME, in: The UNEP Large marine ecosystem report: a perspective on changing conditions in LMEs of the world's regional seas. UNEP Regional Seas Report and Studies 182, edited by: Sherman, K. and Hempel, G., UNEP, Nairobi, Kenya, 735-746, 2009.

Lutz, V. A., Segura, V., Dogliotti, A. I. Gagliardini, D. A., Bianchi, A. A., and Balestrini, C. F.: Primary production in the Argentine Sea during spring estimated by field and satellite models. J. Plankton Res., 32, 181-195, doi:10.1093/plankt/fbp117, 2010.

Matano, R. P. and Palma, E. D.: The upwelling of downwelling currents, J. Phys. Oceanogr., 38, 2482-2500, doi:10.1175/2008JPO3783.1, 2008.

Matano, R. P., Palma, E. D., and Piola, A. R.: The influence of the Brazil and Malvinas currents on the southwestern Atlantic shelf, Ocean Sci., 6, 983-995, doi:10.5194/os-6-983-2010, 2010. 
Palma, E. D., Matano, R. P., and Piola, A. R.: A numerical study of the Southwestern Atlantic Shelf circulation: stratified ocean response to local and offshore forcing, J. Geophys. Res, 113, C11010, doi:10.1029/2007JC004720, 2008.

Parker, G., Paterlini, C. M., and Violante, R. A.: El fondo marino, in: El Mar Argentino y sus Recursos Marinos, INIDEP, Mar del Plata, edited by: Boschi, E., Argentina, 65-87, 1997.

Romero, S. I., Piola, A. R., Charo, M., and Garcia C. A. E.: Chlorophyll-a variability off Patagonia based on SeaWiFS data, J. Geophys. Res., 111, C05021, doi:10.1029/2005JC003244, 2006.

Saraceno, M., Provost, C., and Piola, A. R.: On the relationship between satellite-retrieved surface temperature fronts and chlorophyll a in the western South Atlantic, J. Geophys. Res., 110, C11016, doi:10.1029/2004JC002736, 2005.

Sea-Bird Electronics Inc., Application Note NO. 64-2, SBE 43 Dissolved Oxygen Sensor Calibration using Winkler Titrations, SeaBird Electronics Inc., Bellevue, Washington, USA, 6 pp., October 2002.
Sea-Bird Electronics Inc., SEASOFT-Win32: SBE Data Processing, CTD Data Processing and Plotting Software for Windows 95/98/NT/2000/XP, Software Release 5.34a and later, Sea-Bird Electronics Inc., Bellevue, Washington, USA, 124 pp., May 2005.

Sea-Bird Electronics Inc., Application Note NO. 31, Computing Temperature and Conductivity Slope and Offset Correction Coefficients from Laboratory Calibrations and Salinity Bottle Samples, Sea-Bird Electronics Inc., Bellevue, Washington, USA, 7 pp., February 2010.

UNESCO: The Practical Salinity Scale 1978 and the International Equation of State of Seawater 1980. UNESCO Tech. Papers, Mar. Sci., 36, 25 pp., 1981. 